\begin{tabular}{l}
\hline Elena Pellús \\
Licenciada en Filología Hispánica en la \\
Universidad de Alicante (1994-1998). Su \\
labor investigadora se ha materializado en \\
la tesis de licenciatura titulada «Hernán \\
Cortés desde la historiografía de Indias: in- \\
troducción, estudio y traducción del texto \\
De rebus gestis Ferdinandi Cortesii», di- \\
ciembre de 2002. Con anterioridad fue be- \\
caria del Instituto Juan Gil-Albert para la \\
realización del proyecto Elaboración de \\
proyectos multimedia sobre la ciudad (pre- \\
paración de materiales, prácticas de ela- \\
boración, primer resultado) en los años \\
1996 y 1997) y becaria de investigación de \\
la Universidad de Alicante para la Biblio- \\
teca Virtual de la Universidad de Alicante, \\
(diciembre de 1998-febrero de 1999). En la \\
actualidad continúa su investigación sobre \\
la historiografía de Indias. \\
\hline
\end{tabular}

\section{1}

La referencia a la canción peruana procede de D. R., «Raíces incas Makamaru». La referencia de Pablo Neruda puede encontrarse en P. Neruda, «Alturas de Machu Pichu» apud Obras completas, Barcelona, Galaxia Gutenberg, Círculo de Lectores 1999, pág. 444.

2

A. Zitarrosa, Antología (19361979), Argentina, Sony Music, 1979.

3

J. C. Rovira, José Toribio Medina y su fundación literaria y bibliográfica del mundo colonial americano, Santiago de Chile, Dibam, Biblioteca Nacional de Chile, Centro de Investigaciones Diego Barros Arana, 2002, págs. 27 y ss.

Construcción y destrucción de dos culturas: aztecas y españoles en tres relatos de Carlos Fuentes

ELENA PELLÚS

\title{
CONSTRUCCIÓN Y DESTRUCCIÓN DE DOS CULTURAS: AZTECAS $Y$ ESPAÑOLES EN TRES RELATOS DE CARLOS FUENTES
}

\author{
ELENa PELLÚs
}

A fines del siglo XX, cuando el primer milenio cierra sus puertas, el escritor mexicano Carlos Fuentes publica su obra Los cinco soles de México. En poco más de cuatrocientas páginas se recoge la memoria de un pueblo $y$, consciente del crepúsculo de una época, como subtítulo de la citada obra, aparece la aclaración: Memoria de un milenio. El escritor nos va contando la historia a través de breves capítulos, pertenecientes cada uno de ellos a diferentes momentos de la cronología mexicana. Las narraciones funcionan aquí como ventanas que se abren hacia el pasado, y el lector se zambulle en una lectura de progresivos planos históricos que van sucediéndose y superponiéndose hasta configurar un discurso completo: el de la historia del pueblo mexicano.

Desde el siglo XIX hasta hoy, múltiples son las voces que se alzan a uno y otro lado del océano reivindicando las huellas de un tiempo que durante siglos les ha sido negado, y que resulta necesario para encontrar el origen de todo un continente (el americano). Algunas de esas voces recurrentes evocan fragmentos de un tiempo solapado y adquieren su verdadero significado cuando son rescatadas a través de los sentidos, o de la razón, y son contempladas desde otra perspectiva.

La canción Raíces incas Markamaru suena mientras esto escribo, y evoca, por ejemplo, la imagen de la cumbre incaica, desde la que un intemporal Pablo Neruda grita: «Pie- dra sobre piedra, y el hombre, ¿dónde estaba? $\gg^{1}$. Cuando el poeta chileno increpa al tiempo y al hombre desde Alturas de Machu Pichu no sólo está utilizando un recurso poético, también está recuperando un pasado escondido. Cuando, desde el oriente americano, Alfredo Zitarrosa nos saluda con sus Diez décimas, y canta aquello de «No hay cosa más sin apuro que un pueblo haciendo su historia» está utilizando de nuevo ese mismo recurso: está proyectando la historia mediante el lenguaje $e^{2}$.

El camino hacia el pasado no es solamente un mecanismo evocativo que utilizamos aquí gratuitamente. La recuperación en el siglo XX de las literaturas del pasado se enmarca en el ámbito de la historia de la literatura, y parte de una revisión del método interpretativo que dota a los textos de nuevas posibilidades epistemológicas ${ }^{3}$. Tanto el rescate de las culturas precolombinas como el testimonio de los textos coloniales deberá realizarse desde el método histórico-literario, porque sólo desde un planteamiento que permita poner de manifiesto las interpretaciones no sólo literarias, sino también históricas, sociales, antropológicas, de los textos literarios, podremos indagar en el testimonio de una época que nos ha llegado confusa, y aportar así nuevas claves de las literaturas del pasado.

Desde esta óptica, las palabras de Carlos Fuentes se presentan como un instrumento 
válido de recuperación de las significaciones que explican nuestro tiempo. En la obra Los cinco soles de México encontramos una visión sorprendente de la historia del norte de Latinoamérica, contada desde la subjetividad de la memoria y desde la identificación con una nación que le pertenece, y narrada, asimismo, desde la génesis hasta el crepúsculo contemporáneo.

Carlos Fuentes quiere escribir la historia que se esconde tras la espalda de México como si fuera un profeta del tiempo. Para ello, mira hacia atrás, y recupera, de lo que ve, sólo aquello que desea mirar, aquello que obedece y sirve a sus propósitos. La síntesis de lo que hace Carlos Fuentes en los Cinco soles de México la encontramos -simbólicamente, claro está- en un verso del poeta chileno Gonzalo Rojas en el que adivina al lector, y exclama: «Soy, pues, el perro que adivina el porvenir: profetizo» ${ }^{4}$.

La escritura de los Cinco soles de México es versátil y se adapta a las necesidades de cada fragmento de la historia que se ha seleccionado. En algunos relatos evoca la manera de contar las antiguas historias y rescata la visión ontológica propia del pensamiento azteca; entonces la mitología y el tono poético se sitúan en el primer plano. En otros momentos increpa al lector y lo cuestiona, conduciéndolo al terreno reflexivo. En otros casos, el tono narrativo se antepone a los demás y estructura la historia, como sucede, por poner un caso, en el relato «La independencia». En otras ocasiones el escritor prefiere la prosa testimonial o de denuncia, y arremete sin tapujos contra aquello de lo que discrepa. En total, veintitrés relatos, con un Prefacio y un Epílogo, completan la obra del mexicano. Los relatos, que podrían funcionar como capítulos independientes unos de otros, guardan sin embargo relación entre ellos y funcionan con una estructura común, que viene dada por la historia latente que permanece como trasfondo del libro, la historia de México.

Hemos escogido tres relatos que aparecen en esta obra y que se sitúan en tres estadios diferentes de la historia. El primero de ellos, que se identifica con la época prehispánica y lleva por nombre «Chac Mool», se construye como una alegoría narrativa de la imagen del eterno retorno, contada desde la sorpresa. «Las dos orillas» es el título del segundo relato, que se presenta como un testimonio ficcional de la

experiencia de Jerónimo de Aguilar durante la conquista, y como una descripción válida de las acciones llevadas a cabo por Hernán Cortés. «La Malinche» es el tercero de los relatos analizados, y se inserta en el momento del mestizaje de las culturas española y azteca, como una síntesis del resentimiento del pueblo mexicano.

Vamos a analizar, porque conviene a nuestros propósitos, la historia de «La Malinche» en primer lugar, y dejaremos para el final el relato de «Chac Mool».

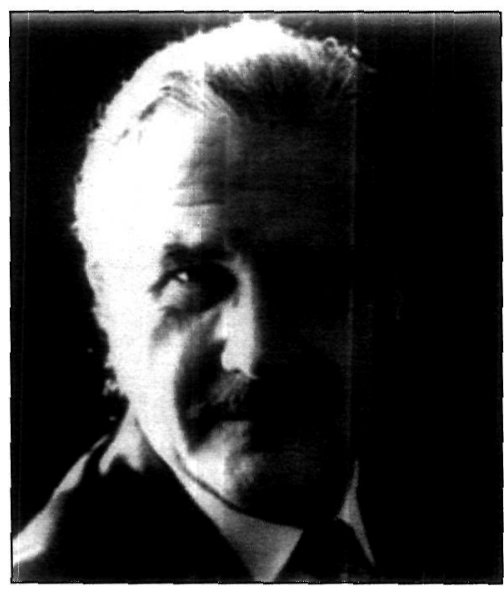

Carlos Fuentes.

\section{ER RELATO}

\section{EL MESTIZAJE. «LA MALINCHE $»^{5}$}

El relato de La Malinche ocupa el cuarto lugar en los relatos del libro, y es el más breve de todos ellos; su extensión no alcanza dos páginas. Está escrito como un monólogo exhortativo que verbaliza el quejido doloroso de Marina en el momento del parto. El discurso que se pone en boca de la mujer sale como un vómito de palabras que caen sobre el hijo naciente: México. El simbolismo, por tanto, estructura el discurso, y desde ahí debe ser interpretado. El ritmo de la prosa es aquí ágil, dinámico, casi atropellado: apenas aparecen cuatro pausas fuertes en una redacción estructurada como un único párrafo.

Malintzin, o si se prefiere, Marina, ha sido y sigue siendo utilizada desde la conquista hasta nuestros días como símbolo polivalente; real, a veces, peyorativo otras, pero siempre contradictorio y cargado de significado. Mucho se ha comentado y especulado sobre su figura, pero poco se la ha estudiado. Sin duda, la masculinidad histórica se impone y ha querido que ocupe un lugar secundario en la historia de México. Sabemos muy poco de ella porque los hombres que escribieron sobre la conquista poco escribían sobre el papel funcional de las mujeres en la sociedad. Octavio Paz le dedicó un espacio de su obra El laberinto de la soledad. Georges Baudot escribió un brillante artículo sobre la que ha sido y es considerada la mujer de la conquista. En dicho artículo, Baudot nos ofrece algunas claves para recuperar una imagen justa de Malintzin. Queremos recoger, a propósito del relato, algunas de estas claves. En primer lugar, el proceso de mitifica-
4

«Sartre» en G. Rojas, Metamorfosis de lo mismo, Madrid, Visor, 2000, pág. 44.

5

C. Fuentes, Los cinco soles de México, Barcelona, Seix-Barral, 2000, págs. 81-82.
Construcción y destrucción de dos culturas: aztecas y españoles en tres relatos de Carlos Fuentes ELENA PELLÚS 


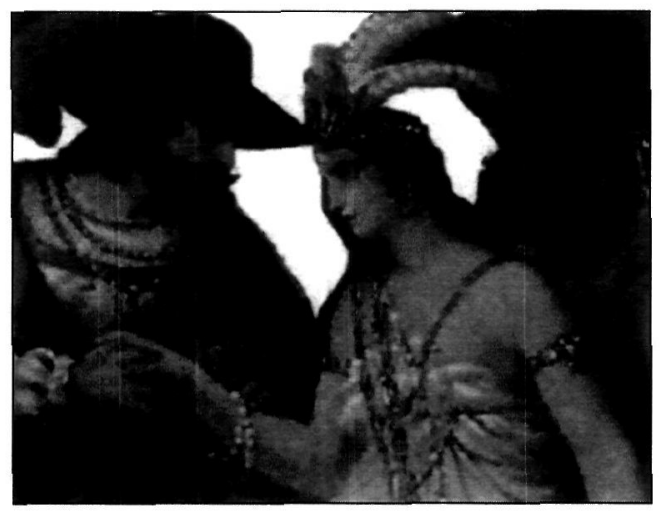

La Malinche.

6

G. Baudot, «Política y discurso en la conquista de México: Malintzin y el diálogo con Hernán Cortés», apud AA.V., Hernán Cortés y su tiempo. Actas del Congreso Hernán Cortés y su tiempo, $V$ Centenario (1485-1985), Mérida, Editora Regional de Extremadura, 1987, pág. 626.

7

B. DÍAZ DEL CASTILLO, Historia verdadera de la conquista de la Nueva España, Barcelona, Akal, 1998, (prólogo de Francisco Rico), cap. XXXVI.

\section{8}

Op. cit. B. Díaz del Castillo, capítulos LXXII-LXXVII.

9

Op. cit. C. Fuentes, pág. 82.

10

Ibidem.

Construcción y destrucción de dos culturas: aztecas y españoles en tres relatos de Carlos Fuentes ELENA PELLÚS ción de la Malinche empieza en el siglo XX, y no antes. Dice Baudot:

Y si todos sabemos que la historia de una nación forja los mitos que luego son el tejido de una conciencia colectiva de identidad nacional, en el caso que nos ocupa, los datos de la vivencia histórica han sido re-elaborados de un modo muy peculiar para lograrlo $0^{6}$

En segundo lugar, en lo que se refiere a las crónicas de Indias, los que mejor material parecen aportar son Bernal Díaz del Castillo y Francisco López de Gómara -además del propio Cortés, claro está-. Tanto Bernal Díaz como López de Gómara resaltan la inteligencia y nobleza de carácter de esta mujer, y Bernal Díaz le dedica el capítulo XXXVII de su crónica'. En cuanto a la relación de Hernán Cortés, el espacio que deja el extremeño en sus Cartas al emperador es tan breve y superfluo, que resulta excesivamente elusivo para el papel que ocupó esta mujer no sólo en el proceso de dominación, sino también en la vida personal del conquistador. Los silencios de Cortés resultan más reveladores que sus palabras, porque nos indican que hay un interés implícito en no contar apenas nada sobre Malintzin. Quizá se deba a una voluntad de contrarrestar la función esencial de Marina en la conquista, quizá también, se deba a la imposibilidad de reconocer ante el emperador que la victoria se había logrado gracias al apoyo de una mujer, porque sin duda alguna ella fue un arma poderosa.

En tercer lugar, como señala Baudot, resulta muy significativo el hecho de que los textos amerindios se refieran a Hernán Cortés como el «capitán Malinche». También las crónicas de Indias nos revelan que el apodo de Malinche fue utilizado para referirse a Hernán Cortés$^{8}$. Y precisamente con ese apodo ha perdurado hasta hoy el personaje de Malintzin. La onomástica constituye una huella muy representativa del sincretismo de dos culturas enfrentadas, la española y la azteca, porque la forma que se ha impuesto no es ni la castellana ni la nahuatl, sino la sincrética «Malinche». Tenemos, por tanto, que el término empleado para denominar al español que dirigió la conquista se aplica también a la mujer que le ayu- dó a lograr su empresa, y precisamente con esa forma nos ha llegado hasta hoy.

Volvamos al relato de Carlos Fuentes. Como ya se ha dicho, en el texto, México es representado como el hijo ilegítimo de la $\mathrm{Ma}$ linche. A través del símbolo nacional del mestizaje que representa la mujer, Carlos Fuentes habla a su México natal con la confianza y el cariño de una madre, y utiliza expresiones como: «adorado hijo mío», «hijito mío», o «hijo de la madrugada», pero también se dirige a él con la irreverencia y dureza que nacen del dolor, y lo llama: «hijo de la traición», «hijo de puta», «hijo de la chingada».

Carlos Fuentes transpone su propio discurso en el de Malinche, $y$, consciente de que el peso de la historia cae sobre él, le advierte del dolor futuro, y le dice:

contra todos deberás luchar y tu lucha será triste, porque pelearás contra una parte de tu propia sangre?

El escritor habla desde la conciencia de sus raíces culturales, y construye un retrato de la nación mexicana sobre una sucesión de adjetivaciones constantes, describiéndolo como: ilegítimo, esclavo, servil, padeciente, burlado, blanco, moreno, falsamente sumiso, rencoroso, temeroso, vengativo, desconfiado, paciente. Le dice, por ejemplo:

«sabrás esperar, esperar como nuestros ancestros esperaron la llegada de la serpiente con plumas» ${ }^{10}$.

Se trata de la espera de la venganza de su propia historia traicionada.

Por último, hay que señalar que, a pesar del silencio inevitable que cubre la figura de Malintzin, el valor principal reconocido de la mujer de la conquista es, paradójicamente, el valor de la palabra, y por él ha sido mitificada y condenada. La Malinche reparte la palabra en ese momento crucial de la historia de un continente, y ella es quien aparece retratada como figura central en los códices indígenas. Ella es quien -siguiendo la imagen clásica de la traducción como traducere navem- lleva la nave de orilla a orilla en ese río intercultural que se inaugura en la conquista. Con la $\mathrm{Ma}$ linche nace un nuevo discurso, el de la transculturación, e, ironías de la vida, la historia ha querido que el sincretismo y el mestizaje, sobre los que se sustenta el pueblo mexicano, tengan nombre de mujer. 


\section{$2^{\circ}$ RELATO}

\section{LA CONQUISTA ESPAÑOLA. «LAS DOS ORILLAS»11}

Vayamos ahora, situados en ese momento apasionante de la conquista, al relato que ocupa el tercer lugar dentro del libro. Su protagonista, Jerónimo de Aguilar, ejerce también un lugar principal en ese diálogo que se establece entre las dos culturas transatlánticas. Se presenta como un testimonio de la experiencia de Jerónimo de Aguilar durante la conquista, y como tal, está narrado en primera persona. La historia nos cuenta desde el presente lo que sucedió en el pasado.

El lector va adivinando al narrador anónimo progresivamente, a través de los datos que desgranados nos va dando sobre sí mismo. Por una alusión a la Córdoba natal sabemos de su origen español. Unas líneas más abajo, se nos dice que la voz que nos habla es una voz de ultratumba-como aquellas que se han levantado en otras ocasiones desde el páramo mexicano-. Sólo algunas páginas más tarde el narrador nos dirá su nombre. Mediante este recurso narrativo, presente a lo largo del relato, Carlos Fuentes logra situarse al margen de lo que se cuenta, y acerca el ojo del lector a la boca de quien nos habla.

El discurso empieza con una frase directa, clara y concisa: «Yo vi todo esto» ${ }^{12}$. Desde aquí, todo se elabora en torno a un propósito principal: el de convencernos de la veracidad histórica de lo narrado y posicionarnos a favor de quien escribe. Está dividido estructuralmente en epígrafes numerados en orden descendente, que van desde el diez, hasta el cero. El primero le sirve para presentar la historia y situar al lector en el entorno de la conquista. El último epígrafe constituye una reflexión sobre lo que se acaba de contar. Uno y otro tienen un tono testimonial más acusado que los epígrafes restantes, que adquieren un tono mayoritariamente narrativo.

Carlos Fuentes evoca con su discurso la escritura de los cronistas de Indias, en las que el objetivo principal siempre es el mismo: convencer al lector de que la versión propia es la más veraz. El recurso sugerente es una constante en el relato, y la seducción se logra a través de varias vías. En el plano gramatical, las evocaciones sensoriales se consiguen mediante la adecuación de los recursos morfológicos a los propósitos efectistas. Los planos verba- les van acercando la historia al lector, dependiendo de la intención del autor. Un ejemplo: el pasado indefinido de la primera persona que nos dice al principio del relato: «Yo vi todo esto", pasa a ser pretérito perfecto dos párrafos después: «Lo he visto todo» ${ }^{13}$. Pongamos otro ejemplo: el pasado reiterativo que se emplea en la descripción de la caída de Tenochtitlan: «cayeron los dioses», «cayeron los templos, las insignias, los trofeos» ${ }^{14}$, se abandona por la forma perifrástica en las referencias al trauma de la conquista: «Europa le ha arañado para siempre el rostro a este Nuevo Mundo», o por el tiempo presente y el futuro en las exhortaciones al lector, como cuando pregunta: «¿Cuánto durarán las nuevas mansiones de nuestro único Dios?» ${ }^{15}$.

En segundo término, se van confrontando a lo largo del relato la tradición indígena y la tradición europea. A través, por ejemplo, de comparaciones, como la de los cuatro dioses aztecas: «Lluvia», «Agua», «Viento», y «Fuego» coincidentes con los cuatro elementos de la naturaleza, a los que se añade al final, uno más: el dios «Basura». Las descripciones también se elaboran desde las evocaciones significativas. La descripción de la caída de Tenochtitlan se hace a partir de tres metonimias: «el rumor de los atabales», «el choque de acero contra el pedernal», y «el fuego de los cañones castellanos». Una última alusión al «agua quemada de la laguna» completa el cuadro de la conquista.

A las descripciones de la nueva sociedad que se está formando, la mexicana, hay siempre asociado un tono negativo, ya sea en la manera de expresar la derrota de los indígenas, en la codicia de los españoles por el oro de Moctezuma, o en el contagio de las enfermedades: «me maravilla ver, de la noche a la mañana, esta ciudad de México poblada de rostros cacarañados».

En tercer lugar, Carlos Fuentes introduce la magia y la ficción como parte de esa intención de convencer al lector. Recordamos, por citar un caso, las palabras que dicen: «quien sienta curiosidad o sea topo encontrará en la base de las columnas de la catedral de México las divisas mágicas del dios de la noche, el espejo humeante de Tezcatlipoca» ${ }^{16}$. Como vemos, la prosa de Carlos Fuentes es plenamente consciente de su propósito.

Por otra parte, la religión ocupa un lugar fundamental desde el principio del relato. Sin
11

Op. cit. C. Fuentes, 2000, págs. 43-80.

12 Ibidem, pág. 43.

13 Ibidem, págs. 43-44.

14

Ibidem, pág. 43

15 Ibidem, pág. 44 y pág. 43, respectivamente.

16

Ibidem, pág. 43
Construcción y destrucción de dos culturas: aztecas y españoles en tres relatos de Carlos Fuentes ELENA PELLÚS 
18

Ibidem, pág. 58.

19

Es un hecho, no refutado pero sí habitual entre los lectores de crónicas, que la crónica de Bernal Díaz es la que suele tomarse como la más fiable de entre todas, debido, probablemente, al origen social de quien escribe, al estilo de su prosa, y a la aclaración en el título de "verdadera" historia. Estamos de acuerdo, sin embargo, con Ángel Delgado, quien continúa con la línea planteada por Francisco Rico, cuando dice que Bernal Díaz es perfectamente consciente de las técnicas que emplea a la hora de escribir su relación, técnicas que emplea al servicio del fin último de todas las crónicas: convencer al lector. Op. cit. anterior ( $\left.n^{\circ} 7\right)$.

20

Ibidem, pág. 44.

21

Ibidem, pág. 43.

22

Sobre Pedro Escudero, Juan Cermeño y Gonzalo de Umbría también hablan Francisco Cervantes de Salazar y Francisco López de Gómara. Recogemos aquí el fragmento del primero, por ser posterior, y porque él recoge la versión de Francisco López de Gómara: "Cortés, entendida la conjuración, viendo que convenía antes que más se afistolase la llaga cortar algunos miembros, mostrando, porque así convenía, más enojo del que tenía en su pecho, prendió muchos dellos y con grande aviso, tomándoles su confesión, hallando ser unos más culpados que otros, les dio diversas penas, porque ahorcó a Joan Escudero y a Diego Cermeño, piloto, grandes cortadores de espada... Mandó cortar el pie a otro y azotar a otros dos, que fueron Gonzalo de Umbría y Alonso Peñate» Fco. CERVANTES DE SALAZAR, Crónica de la Nueva España, Alicante, Biblioteca Virtual Miguel de Cervantes Saavedra, 2000, edición digital a partir de la edición Madrid,

Construcción y destrucción de dos culturas: aztecas y españoles en tres relatos de Carlos Fuentes ELENA PELLÚS

embargo, la mención religiosa no es explícita, sino que está condicionada, de nuevo, por la sutilidad de las alusiones. Por ejemplo, cuando el soldado español afirma que: «los españoles matamos algo más que el poder indio: matamos la magia que lo rodeaba» ${ }^{17}$. También aparecen en las intervenciones de otros personajes; por ejemplo, en la exclamación de los papas a la entrada de los españoles en Cholula «iAun no entran y ya nos piden traicionar a los dioses!» ${ }^{18}$.

En la escritura de "Las dos orillas» Carlos Fuentes se acerca, de entre todos los cronistas, a Bernal Díaz del Castillo más que a ningún otro. No solamente en el tono testimonial y en las semejanzas de los narradores -en ambos casos habla un soldado español que participó en la conquista junto a Hernán Cortés- sino también porque constituye la fuente principal por la que Carlos Fuentes parece dejarse guiar. De

Atlas, 1971, capítulo XXI. Francisco López de Gómara dice sobre el mismo punto: «Cortés entonces se enojó de veras. Prendió muchos de ellos; tomoles por sus dichos, en que confesaron ser verdad aquello. Por lo cual condenó los más culpados, según el proceso y tiempo; ahorcó a Juan Escudero y a Diego Cermeño, piloto; azotó a Gonzalo de Umbría, que también era piloto, y a Alonso Peñate. A los demás no tocó. Con este castigo se hizo Cortés temer y tener en más que hasta alli’. Fco. López de Gómara, Historia de la conquista de México, México D. F., Porrúa, 1997, capítulo XLI, «EI motín que hubo contra Cortés, y el castigo».

23

«Hecho este aucto y diligencia, nombró luego por Alcaldes a Puerto Carrero y a Montejo; por Regidores a Alonso de Ávila, a Alonso de Grado, a Pedro de Alvarado y a Escalante, y por Procurador general a Francisco Álvarez Chico, que era hombre de negocios y por Alguacil mayor a Gonzalo de Sandoval, y por escribano de Cabildo a un Godoy”. Fco. Cervantes de Salazar, Crónica de la Nueva España, 2000, capítulo VIII, «Del razonamiento que Cortés hizo a los suyos y de la elección de Cabildo en la Veracruz». Bernal Díaz dice en el capítulo XCVI de su crónica que después de haberlo enviado como capitán de la plaza de la Veracruz, éste se excedió en sus funciones e intentó engañar a Cortés en favor de Diego Velázquez. Pero cuando Hernán Cortés lo supo, envió a Gonzalo de Sandoval a por él y lo tuvo en el cepo durante un tiempo. Op. cit. B. Díaz del Castillo, 1998, cap. XCVI.

\section{4}

Fco. Cervantes de Salazar, Crónica de la Nueva España, 2000, capítulo LI, «Cómo Cortés otro día mandó llamar a todos los suyos y del razonamiento que, leídos los nombres del papel, les hizo».

25

Tal y como nos cuenta un poco después, es uno de los hombres a los que confió el dinero que debía enviarse a Castilla: Muchos inviaron dineros a sus parientes, e Cortés invió cuatro mill ducados a sus padres con Joan de Ribera, su secretario. Llevaron esta riqueza Alonso de Ávila e Antonio de Quiñones, Procuradores generales de México y de todo lo conquistado Fco. Cervantes de Salazar, Crónica de la Nueva España, 2000, capítulo III, «De lo que se hubo del despojo de México, y de lo que cupo al Emperador de su quinto». la misma manera que sucede con Bernal Díaz del Castillo, el tono aparentemente veraz es justamente eso, sólo apariencia ${ }^{19}$.

En cuanto a la presencia de las crónicas de Indias en el texto, si bien no se especifican las fuentes consultadas, son evidentes las referencias a la historiografía de Indias que aparecen en la narración: a Bernal Díaz del Castillo, a Francisco López de Gómara, a Francisco Cervantes de Salazar, a la relación de Hernán Cortés... Sin embargo, solamente se reconoce explícitamente la presencia de la crónica del soldado de Medina del Campo. Dice Jerónimo de Aguilar: «cincuenta y ocho veces soy mencionado por el cronista Bernal Díaz del Castillo en la Historia verdadera de la Conquista de la Nueva España» ${ }^{20}$. El escritor mexicano utiliza expresiones del cronista, como por ejemplo, la anteriormente mencionada «en medio del rubor de atabales», que es una de las más conocidas y citadas de Bernal Díaz $^{21}$. De entre los nombres que participaron en la conquista encontramos, por ejemplo, a Pedro Escudero y Juan Cermeño, dos de los soldados a los que Cortés ejecutó después de la conjuración que contra él se estaba preparando (Pedro Escudero y Juan Cermeño pensaban contarle a Diego Velázquez el propósito que tenía Cortés de poblar el territorio y nombrarse capitán). Junto a estos dos nombres se menciona también a Gonzalo de Umbría, a quien el conquistador cortó un pie como castigo. Carlos Fuentes escoge conscientemente los personajes que ponen en evidencia la crueldad de Cortés, porque eso es precisamente lo que quiere poner de relieve ${ }^{22}$. De cada uno de los hombres mencionados en el relato, destaca solamente el dato que le resulta útil. De Alfonso de Grado, por ejemplo, otro de los nombres que aparecen en la narración, sabemos por Cervantes de Salazar que era uno de los principales del conquistador, y que lo nombró Cortés regidor en la elección del cabildo de Veracruz ${ }^{23}$. De Quiñones, por ejemplo leemos que Cortés:

andaba de noche y de día con alguna guarda de los más amigos, cuyo Capitán era un Fulano de Quiñones ${ }^{24}$.

Su nombre de pila, que no se dice en el relato de "Las dos orillas», era Antonio ${ }^{25}$. A Juan Florín, el pirata francés que robó el primer envío de oro que viajaba hacia Castilla 
bajo el mando de Alonso de Ávila -y no de Dávila, como escribe Carlos Fuentes- lo encontramos en la crónica de Francisco Cervantes de Salazar, y en la Historia de la Conquista de México, de Francisco López de Gómara ${ }^{26}$. Era este Alonso de Ávila uno de los que viajaron en la primera expedición con Juan de Grijalva ${ }^{27}$. Alonso de Grado era también cercano al círculo de Cortés. Es, por ejemplo, uno de los firmantes de la Tercera carta de relación ${ }^{28}$. Del piloto Cárdenas, de quien cuenta Carlos Fuentes que denuncia al conquistador en Castilla, nos dice Bernal Díaz del Castillo que era uno de sus soldados, y que fue uno a los que Cortés dio trecientos pesos para que se fuese con su mujer e hijos a Cuba ${ }^{29}$.

En «Las dos orillas» se hace hincapié en la importancia del lenguaje como instrumento esencial del proceso de conquista. Precisamente por este motivo es Jerónimo de Aguilar, y no otro, quien nos cuenta la historia. Él es quien vierte del maya al español, y quien, con Marina, hace posible la comunicación entre Cortés y Moctezuma.

Carlos Fuentes presenta a un Jerónimo de Aguilar que reconoce haber mentido: «traduje, traicioné, inventé», pero también dibuja un Cortés que convierte en realidad la crueldad de las palabras inventadas por el traductor, volviendo verdad lo que no lo era:

mas como así sucedió, en efecto, convirtiéndose mis falsas palabras en realidad, ¿no tuve razón en traducir al revés al capitán y decirle, con mis mentiras, la verdad al azteca? ${ }^{30}$

El soldado español es consciente de poseer el don de la palabra. Lo encontramos en manifestaciones tales como «la versión castellana que llegaba a los oídos del conquistador, era siempre la mía» ${ }^{31}$; o en reiteradas afirmaciones como «en las costas de Tabasco, yo fui la única lengua», y en otras referidas a su rivalidad con doña Marina. También cuando, tras la aparición de Malintzin, declara que

«fue entonces que la segunda lengua del conquistador, una princesa esclava de Tabasco bautizada doña Marina, pero apodada la Malinche, interpretó velozmente.... ${ }^{32}$, o cuando dice:

redescubrí mi propia lengua, la que fluyó hacia mis labios desde los pechos de mi madre castellana, y en

seguida aprendí el mexicano, para poder hablarle a los aztecas. La Malinche siempre se me adelantón ${ }^{33}$

Las palabras de Carlos Fuentes nos sirven como pretexto para insistir una vez más en el valor del lenguaje como soporte referencial de la memoria. La intemporalidad de la conquista española está marcada por la destrucción y la construcción de dos mundos, el azteca y el mestizo, que contrapuestos y paradójicamente unidos entre sí por el Nuevo Mundo, son identificadores de la sociedad del pasado y del presente. La historiografía de Indias se configura como un corpus textual que inaugura el proceso de recuperación del pasado, porque funciona como un mecanismo de conservación de ese episodio histórico, y con ello, de recuperación de la cultura precolombina y colonial. Si el primer gesto de recuperación de la memoria americana lo constituyen las crónicas de Indias, Carlos Fuentes las utiliza para reivindicar la historia de un continente y, más concretamente, la historia de México.

\section{$3^{\text {ER }}$ RELATO}

\section{EL ETERNO RETORNO. «CHAC MOOL ${ }^{34}$}

El narrador sitúa la acción en el siglo XX, poco después de Semana Santa. No se especifica el día; quizá porque podría ser cualquiera de los que pertenecen a nuestra cotidianidad. Filiberto ha muerto ahogado en Acapulco. A partir de las preguntas que se hace el narrador tras la muerte de su amigo, vamos conociendo las respuestas que han quedado sin resolver tras su muerte:

\section{6}

El primer envío de dinero para Castilla iba: "en tres carabelas, los dos de las cuales que llevaban el tesoro, tomó, por gran ventaja que llevaba, un cosario francés llamado Florín, y esto más allá de las islas de los Azores, el cual casi en el mismo tiempo tomó también otra nao que iba de las islas con setenta y dos mill ducados, seiscientos marcos de aljófal y perlas y dos mill arrobas de azúcar». Fco. Cervantes de Salazar, Crónica de la Nueva España, 2000, capítulo III, «De lo que se hubo del despojo de México, y de lo que cupo al
Emperador de su quinto». Fco. López de Gómara también lo menciona en el capítulo XC de la Historia de la Conquista de México. En el capítulo CXIVII dice: «tomó las dos carabelas que traían el oro Florin, corsario francés, más acá de las Azores y aun también tomó entonces otra nao que venía de las islas, con setenta y dos mil ducados, seiscientos marcos de aljófar y perlas, y dos mil arrobas de azúcar». Fco. López de Gómara, Historia de la conquista de México, 1997, capítulo CXLVII, «El servicio y quinto para el rey, de los despojos de México».
27

«...hizo luego Cortés alarde en Guaniguanigo, y halló quinientos y cincuenta españoles; de los cuales eran marineros los cincuenta. Repartiolos en once compañías, y diolas a los capitanes Alonso de Ávila, Alonso Fernández Portocarrero, Diego de Ordás, Francisco de Montejo, Francisco de Morla, Francisco de Salceda, Juan de Escalante, Juan Velázquez de León, Cristóbal de Olid y un Escobar». Fco. López de Gómara, Historia de la Conquista de México, 1997, capítulo VIII, «Los hombres y navíos que Cortés llevó a la conquista».

28

"De la cibdad de Cuyoacan, a 15 de mayo de 1522 años. Potentísimo Señor, de Vuestra Cesárea Majestad muy humiles siervos y vasallos que los muy reales pies y manos de Vuestra Majestad besan. Julián Alderete Alonso de Grados Bernaldino Vázquez de Tapia» H. Cortés, Cartas de relación, Madrid, Castalia, 1993, pág. 453.

\section{9}

Dice Bernal Díaz del Castillo que «éste fue a quien Cortés dio trecientos pesos para que se fuese a su mujer e hijos; y por excusar prolijidad de ponelles todos por memoria, se fueron otros muchos que no me acuerdo bien sus nombres». Op. cit. B. Díaz del Castillo, 1998, cap. CXXVI.

\section{0}

Op. cit. C. Fuentes, 2000, pág. 49

31

Ibidem, pág. 59.

32

Ibidem, pág. 53.

33

Ibidem, pág. 68.

34

Ibidem, págs. 29-41.
Construcción y destrucción de dos culturas: aztecas y españoles en tres relatos de Carlos Fuentes ELENA PELLÚS 
«quizás, sabría por qué fue declinando, olvidando sus deberes, por qué dictaba oficios sin sentido» ${ }^{35}$.

A través de la lectura de su cartapacio nos introducimos en la historia de Filiberto. Es la historia de un hombre común, con una vida mediocre, al que le gusta coleccionar piezas de arte indígena. Después de adquirir una estatua de Chac Mool, Filiberto es testigo del proceso de encarnación de la estatua, y será víctima de los propósitos del dios de la lluvia.

La recuperación de las culturas precolombinas la logra aquí Carlos Fuentes de varias formas. La primera recuperación la encontramos a través de los diálogos que Filiberto ha plasmado en su diario. Las opiniones de Pepe, el amigo con quien Filiberto conversa sobre México y sobre la vida, revelan el perspicaz sentido del humor y la mirada crítica del escritor. Por ejemplo, la explicación que Pepe ofrece sobre la naturalidad con la que los mexicanos aceptaron el cristianismo de los españoles:

Llegan los españoles y te proponen que adores a un dios, muerto hecho un coágulo, con el costado herido, clavado en la cruz... ¿Qué cosa más natural que aceptar un sentimiento tan cercano a todo tu ceremonial, a toda tu vida? Figúrate, en cambio, que México hubiera sido conquistado por budistas o mahometanos. No es concebible que nuestros indios veneraran a un individuo que murió de indigestión. Pero un dios al que no le basta que se sacrifiquen por él, sino que incluso va a que le arranquen el corazón, ¡caramba, jaque mate a Huitzilopochtli! ${ }^{136}$

La lectura del diario recupera la palabra de Filiberto, ya muerto, que ha dejado escritas conversaciones cotidianas, desde las que se ponen de manifiesto la crítica y la reflexión sobre la condición -mestiza, de nuevo-del pueblo mexicano. Lo que nos está diciendo aquí Carlos Fuentes es que si el cristianismo fue asumido por la población indígena de manera natural, se debió principalmente por las cualidades litúrgicas y de sacrificio de las creencias indígenas, esto es, por lo que la religión cristiana tenía de parecido con la veneración religiosa de los autóctonos: lo sangriento. Por eso dice que: «los aspectos de caridad, amor y la otra mejilla, en cambio, son rechazados». Pepe termina con una sentencia que resume el sentir mexicano:
«Y todo en México es eso: hay que matar a los hombres para poder creer en ellos»37.

La segunda recuperación se plasma en la afición de Filiberto de coleccionar estatuillas y cacharros de arte indígena. Será precisamente la estatua de Chac Mool, que Filiberto llevaba tiempo buscando, la razón de su declive vital, y finalmente de su muerte.

La tercera recuperación se presenta a través de la encarnación de la estatua de Chac Mool, que se va apoderando paulatinamente de la vida de Filiberto, y de su casa. El Chac Mool hace uso de su poder para modificar el recorrido habitual del agua de las cañerías y atraerla hacia el sótano. El dios azteca de la lluvia inunda la casa de Filiberto de agua y de poder: poco a poco se adueñará del espacio y dominará a Filiberto, obligándolo a doblegarse.

El proceso de encarnación del Chac Mool es un proceso lento, del que el lector va tomando consciencia progresivamente por las claves que nos va ofreciendo Carlos Fuentes. Estas claves se organizan de dos maneras. Por un lado, está lo evidente, que es lo que Filiberto nos va contando: los quejidos nocturnos que sólo cesan cuando el sótano está inundado; las sucesivas roturas de las cañerías; el musgo que recubre la estatua; el reblandecimiento progresivo del Chac Mool, que va tomando un aspecto casi humano... Y también están las diferentes escrituras que aparecen en el cartapacio de Filiberto: la escritura habitual, y la escritura a partir del 25 de agosto, cuando la grafía cambia. Por otra parte, encontramos las claves que se anuncian sutilmente, como de soslayo. Por ejemplo, cuando Filiberto deja la estatua en el sótano temporalmente -hasta que encuentre un mejor lugar donde ponerla- y escribe:

«pierde mucho en la oscuridad del sótano, como simple bulto agónico, y su mueca parece reprocharme que le niegue la luz»38.

Entre los recursos narrativos que emplea el mexicano para sugerir la causa de lo que sucede está el léxico. Por citar un caso; al romperse por segunda vez las tuberías, Filiberto escribe que: «las lluvias se han colado, inundando el sótano» ${ }^{39}$.

El cuento de «Chac Mool» es el que mejor representa el proceso de recuperación de las culturas precolombinas, por el marco en el que 
se sitúa -el siglo XX-, y por el argumento. El retorno del dios azteca se plantea aquí como una forma de venganza paulatina y sorprendente, que transgrede los parámetros de realidad y ficción. Carlos Fuentes introduce la ficción en un marco completamente real y cotidiano, y con ese recurso narrativo consigue un doble objetivo. Por una parte, plantea una forma de justicia histórica. La idea del retorno permite a Carlos Fuentes rescatar la mitología indígena del pasado y situarla en el mundo contemporáneo, dotándola de vida humana. Por otra parte, Fuentes nos propone como posible un hecho imposible dentro del espacio de lo real: que la mitología indígena se adueñara de nuestra vidas. Mediante la ruptura de los parámetros aceptados como reales, lo que hace es proponernos una óptica diferente del mundo. Cuando el Chac Mool se ha adueñado por completo de la situación y Filiberto se encuentra invadido y secuestrado en su propia casa, de pronto su vida parece revelarse llena de sentido. Filiberto se cuestiona entonces el plano de lo real como opción válida de vida:
«Todo es tan natural, y luego se cree en lo real». Justo después, el protagonista pasa a validar, en la concepción de su entorno, el plano ficcional frente al real:

hasta hace tres días, mi realidad lo era al grado de haberse borrado hoy: era movimiento reflejo, rutina, memoria, cartapacio. Y luego, como la tierra que un día tiembla para que recordemos su poder, o la muerte que llegará, recriminando mi olvido de toda la vi$d a$, se presenta otra realidad que sabíamos que estaba alli, mostrenca, y que debe sacudirnos para hacerse viva y presente $e^{40}$.

La verdadera recuperación de la historia de México, desde sus orígenes, se consigue cuando el relato biográfico de Filiberto transciende del papel y pasa a formar parte de nosotros, que somos ahora quienes nos preguntamos si la verdad pertenece al plano de lo real, o si, por el contrario, descansa en ese espacio latente de lo ficcional. Filiberto ya se ha convencido. Es momento ahora de que nosotros escojamos. 